\title{
The classification of low-voltage grids with the scenario methodology
}

\author{
J. Teuscher ${ }^{1}$ and W.Schufft ${ }^{1}$ \\ ${ }^{1}$ Chair of Power and High-Voltage Engineering \\ Technische Universität Chemnitz \\ Straße der Nationen 62, 09111 Chemnitz, Germany \\ e-mail: jens.teuscher@etit.tu-chemnitz.de
}

\begin{abstract}
This paper shows the usage of the scenario methodology, a strategic planning tool of the economics, to classify low-voltage grids. The usage gives the result, the population density is the most relevant parameter for planning low-voltage grids. The comparison of these results with real exemplary low-voltage grids confirms this new classification methodology for this use case.
\end{abstract}

\section{Key words}

Low-voltage grids, scenario methodology, classification

\section{Introduction}

In the past the power flow in low-voltage grids was not analysed. But with the development of power flow calculation programs and the increase of the opportunities with these programs the simulation of low-voltage grids is possible. Today this is an interesting research field of distribution grid operators. The new demands for lowvoltage grids based on an increasing of decentralised supply system (e.g. photovoltaic systems) and the connecting of electric vehicles require detailed simulations. Some requests for this simulation are the presumption of the individual consumption in the household and the high number of differences between several low-voltage grids. To manage these demands the classification of low-voltage grids is one option. In this paper the classification is realised with the scenario methodology. This is a strategic planning method for the development of enterprises. The paper gives an overview of the usage from this method to classify low-voltage grids.

\section{Scenario Methodology}

The scenario methodology is a method for strategic planning of enterprises and is used in the research field of economics. Other fields use this method for classification as well.

The scenario methodology is divided in eight main sections, which shows figure 1 . The relevant sections for this paper are the first (problem analysis) and the second part (environmental analysis).

In the problem analysis the situation of the low-voltage grid is described with different parameters.

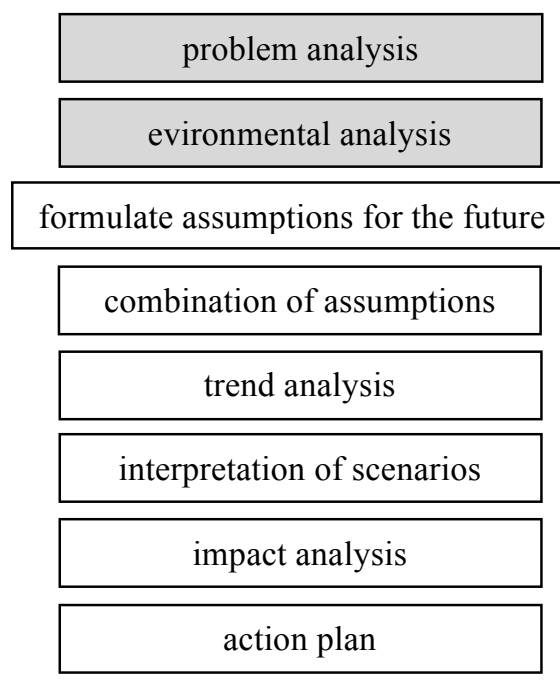

Fig .1 - Structure of the scenario methodology [1]

The environmental analysis describes the relation between these parameters and gives a priority of these parameters. The details of this usage are explained in the following chapter.

\section{Classification of Low-voltage Grids}

\section{A. Problem Analysis}

The problem analysis starts with a description of the lowvoltage grids and a research on the parameters, which characterise every individual low-voltage grid. In different studies low-voltage grids are classified with these parameters. [2], [3] Table III gives an overview about the different parameters. 


\section{B. Environmental Analysis}

The main focus of the environmental analysis is the description of the relations of the in table III specified parameters.

These parameters are compared in the interconnectingmatrix, by list the parameters in the rows and in the columns of the matrix. Table I shows an example of an interconnecting-matrix.

Table I. - Overview of an interconnecting-matrix

\begin{tabular}{|c|c|c|c|c|c|c|}
\hline & 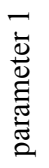 & 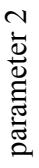 & 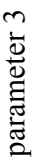 & 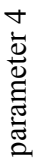 & 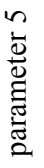 & 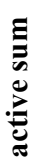 \\
\hline parameter 1 & $\mathrm{X}$ & 0 & 1 & 1 & 1 & 3 \\
\hline parameter 2 & 1 & $\mathrm{X}$ & 0 & 1 & 2 & 4 \\
\hline parameter 3 & 2 & 0 & $\mathrm{X}$ & 2 & 2 & 7 \\
\hline parameter 4 & 1 & 2 & 0 & $\mathrm{X}$ & 2 & 5 \\
\hline parameter 5 & 0 & 1 & 1 & 0 & $\mathrm{X}$ & 2 \\
\hline passive sum & 4 & 3 & 2 & 5 & 7 & \\
\hline
\end{tabular}

The relations between the parameters get a rating of 0,1 or 2. This is an individual choice. If the rating has a high number of subdivisions (e.g. a rating from 0 till 10) the impacts of subjectivities increases. The rating here is based on the dependency between two parameters, see table II.

Table II. - Definition of the rating.

\begin{tabular}{|c|c|}
\hline rating & definition \\
\hline 0 & no relation exist between the parameters \\
\hline 1 & an indirect relation between the parameters, \\
\hline 2 & a direct relation between the parameters \\
\hline
\end{tabular}

Table III. - List of parameters which describe low-voltage grids and the classification with the scenario methodology in four groups and the ranking of priority.

\begin{tabular}{|l|c|c|}
\hline \multirow{2}{*}{$\begin{array}{c}\text { groups of } \\
\text { parameters }\end{array}$} & parameter & rang \\
\hline active & population density & 1 \\
\cline { 2 - 3 } & number of consumers & 2 \\
\cline { 2 - 3 } & size of provided area & 3 \\
\hline ambivalent & number of suppliers & 4 \\
\cline { 2 - 3 } & voltage quality & 5 \\
\hline buffering & grid structure & 6 \\
\cline { 2 - 3 } & kind of supplier & 7 \\
\cline { 2 - 3 } & number of house connections & 8 \\
\cline { 2 - 3 } & kind of consumer & 10 \\
\cline { 2 - 3 } & length of the house connection & 11 \\
\cline { 2 - 3 } & number of main lines & 12 \\
\hline passive & kind of line of the house connection & 13 \\
\cline { 2 - 3 } & length of the main lines & 14 \\
\cline { 2 - 3 } & number of transformers & 15 \\
\cline { 2 - 3 } & number of the sub lines & 16 \\
\cline { 2 - 3 } & listribution of the consumption on the & 18 \\
\cline { 2 - 3 } & & 19 \\
\hline
\end{tabular}

This rating is used by the interconnecting-matrix with the parameters specified in table III. The sum of every row is the active sum of each parameter. Analogous to this the sum of each column results to the passive sum of each parameter.

Figure 2 shows the dependency of the active and the passive sum of each parameter. This figure is called system grid.

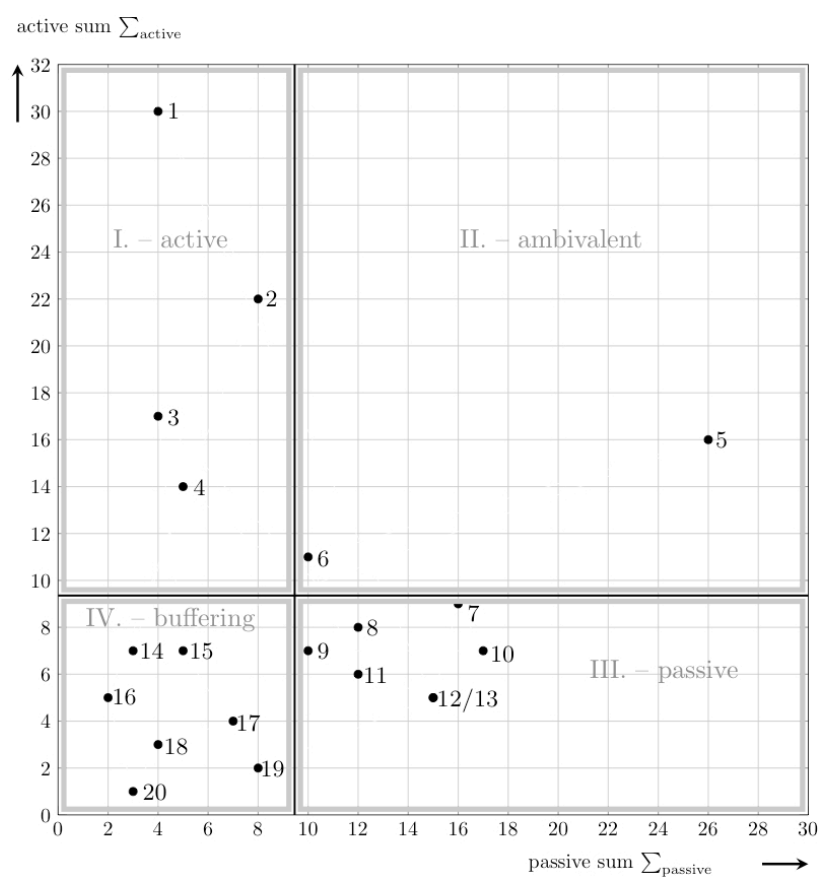

Fig .2 - System grid in addition to table III. [4]

The system grid is divided in four sections. The borders are calculated with the division of the sum of all active or passive sums and the number of parameters. In this system grid both borders are at a value of 9.3 .

With these four sections a prioritisation of the parameters is possible. The parameters with the highest active sum in section I (active) are the parameters with the highest impact of the low-voltage grids. It follows this priority in section II (ambivalent), section III (passive) and section IV (buffering).

The classification shows the population density is the most important parameter for describes the preferences of low-voltage grids. Also the numbers of consumers and suppliers or the size of the provided area have high impacts for the planning of low-voltage grids. Contrary to this, the preferences of the transformer are not relevant for the planning of low-voltage grids. Rather, this parameter depends on other parameter (e.g. the number of consumers).

\section{Comparison the real low-voltage grids}

In the following chapter the results of this classification in comparison to real low-voltage grids are shown. Table IV gives an overview of some parameters of two exemplary low-voltage grids in dependency of the population density (inhabitants $/ \mathrm{km}^{2}$ ) and the number of consumers (households). The big difference in the population density of these two selected grids causes the difference between the maximum lengths of lines. Also 
the comparison between the numbers of consumers shows a direct impact to the respective nominal power of the transformer.

Table IV. - Comparison of some parameters between a rural and an urban low-voltage grid. [5]

\begin{tabular}{|l|c|c|}
\hline parameters & urban LV-grid & rural LV-grid \\
\hline population density & $8.665 \mathrm{inh} . / \mathrm{km}^{2}$ & $136 \mathrm{inh} . / \mathrm{km}^{2}$ \\
\hline number of consumers & approx. 900 & approx. 200 \\
\hline max. lengths of lines & $200 \mathrm{~m}$ & $1400 \mathrm{~m}$ \\
\hline $\begin{array}{l}\text { nominal power of } \\
\text { transformer }\end{array}$ & $630 \mathrm{kVA}$ & $250 \mathrm{kVA}$ \\
\hline
\end{tabular}

This short analysis confirms the classification. For the model building of low-voltage grids the prioritized parameters are the base for the simulation of low-voltage grids.

\section{Conclusion}

The usage of the scenario methodology for a classification of low-voltage grids is possible. The most relevant parameters are the population density, the number of consumers and suppliers and the size of the provided area. The comparison of these results with real exemplary lowvoltage grids confirms this new classification methodology for this use case.

\section{References}

[1] Dönitz, E. J., Effizientere Szenariotechnik durch teilautomatische Generierung von Konsistenzmatrizen, Empirie, Konzeption, Fuzzy- und Neuro-Fuzzy-Ansätze, Gabler GWV Fachverlage GmbH, Wiesbaden 2009, 2009, S.6- 23

[2] Kerber, G. and Witzmann, R., Statistische Analyse von NS- Verteilungsnetzen und Modellierung von Referenznetzen. In: Magazin für die Energiewirtschaft. 2008.

[3] Scheffler, J., Bestimmung der maximal zulässigen Netzanschlussleistung photovoltaischer Energiewandlungsanlagen in Wohnsiedlungsgebieten. Technische Universität Chemnitz. 2002.

[4] Teuscher, J., Leistungsflussoptimierendes Energiemanagement von dezentralen Energieversorgungssystemen in zukünftigen Niederspannungsnetzstrukturen. Universitätsverlag Chemnitz, 2015. ISBN: 978-3-944640-50-1

[5] Teuscher, J., Götz, A. and Schufft, W. Electric vehicles and their effects in low-voltage grids. International Conference on Renewable Energies und Power Quality, Las Palmas de Gran Canaria. 2011. 